\title{
Mapping the bathymetry of supraglacial lakes and streams on the Greenland ice sheet using field measurements and high-resolution satellite images
}

\author{
C. J. Legleiter ${ }^{1}$, M. Tedesco ${ }^{2}$, L. C. Smith ${ }^{3}$, A. E. Behar ${ }^{4}$, and B. T. Overstreet ${ }^{1}$ \\ ${ }^{1}$ Department of Geography, University of Wyoming, Dept. 3371, 1000 E. University Ave., Laramie, WY 82071, USA \\ ${ }^{2}$ Department of Earth and Atmospheric Sciences, The City College of New York, Marshak MR-106, 160 Convent Avenue, \\ New York, NY 10031, USA \\ ${ }^{3}$ Department of Geography, University of California Los Angeles, Box 951524, Los Angeles, CA 90095-1524, USA \\ ${ }^{4}$ Jet Propulsion Laboratory, 4800 Oak Grove Drive, Pasadena, CA 91109-8099, USA
}

Correspondence to: C. J. Legleiter (carl.legleiter@uwyo.edu)

Received: 14 August 2013 - Published in The Cryosphere Discuss.: 26 September 2013

Revised: 1 January 2014 - Accepted: 3 January 2014 - Published: 6 February 2014

\begin{abstract}
Recent melt events on the Greenland ice sheet (GrIS) accentuate the need to constrain estimates of sea level rise through improved characterization of meltwater pathways. This effort will require more precise estimates of the volume of water stored on the surface of the GrIS. We assessed the potential to obtain such information by mapping the bathymetry of supraglacial lakes and streams from WorldView2 (WV2) satellite images. Simultaneous in situ observations of depth and reflectance from two streams and a lake with measured depths up to $10.45 \mathrm{~m}$ were used to test a spectrally based depth retrieval algorithm. We performed optimal band ratio analysis (OBRA) of continuous field spectra and spectra convolved to the bands of the WV2, Landsat 7 (ETM+), MODIS, and ASTER sensors. The field spectra yielded a strong relationship with depth $\left(R^{2}=0.94\right)$, and OBRA $R^{2}$ values were nearly as high $(0.87-0.92)$ for convolved spectra, suggesting that these sensors' broader bands would be sufficient for depth retrieval. Our field measurements thus indicated that remote sensing of supraglacial bathymetry is not only feasible but potentially highly accurate. OBRA of spectra from $2 \mathrm{~m}$-pixel WV2 images acquired within 3-72 $\mathrm{h}$ of our field observations produced an optimal $R^{2}$ value of 0.92 and unbiased, precise depth estimates, with mean and root mean square errors $<1 \%$ and $10-25 \%$ of the mean depth. Bathymetric maps produced by applying OBRA relations revealed subtle features of lake and channel morphology. In addition to providing refined storage volume
\end{abstract}

estimates for lakes of various sizes, this approach can help provide estimates of the transient flux of meltwater through streams.

\section{Introduction}

Recent accelerated melting of the Greenland ice sheet (GrIS) (Tedesco et al., 2013), including a record melt season in 2012 (Nghiem et al., 2012; Bennartz et al., 2013), underscores the need to improve our understanding of the ice sheet's hydrology and thus constrain estimates of the current and future contributions of the GrIS to sea level rise. These estimates are subject to a number of significant uncertainties, many related to the role of meltwater on the surface of the ice sheet. More specifically, two fundamental questions remain unresolved: (1) how much water is stored in supraglacial lakes and streams? and (2) how is this water transferred from the surface to the interior and/or base of the ice sheet, and at what rate? The limited information available for supraglacial water bodies hinders efforts to determine the volume of meltwater present on the surface of the GrIS and hence to develop estimates of meltwater storage and flux. Incorporating this type of information into a hydrologic budgeting framework would help to quantify the proportion of melt that is retained within and/or beneath the ice sheet and that which propagates to proglacial rivers 
and ultimately the ocean (Rennermalm et al., 2013). Motivated by these challenges, this study used simultaneous field measurements and high spatial resolution commercial satellite image data to evaluate the feasibility of measuring the bathymetry of Greenland's supraglacial lakes and streams via spectrally based remote sensing.

Remote sensing is a valuable tool for monitoring the GrIS, with a variety of instruments used to detect and characterize melt (e.g., Nghiem et al., 2012; Tedesco et al., 2013, and references therein). Analysis of satellite images, for example, has provided long-term, synoptic information on patterns of meltwater storage and drainage, establishing the importance of supraglacial lakes as temporary reservoirs (e.g., Liang et al., 2012). Storage volumes have been inferred from remotely sensed data by identifying lakes, measuring their areas, and estimating their depths on the basis of empirical relationships between depth and reflectance (e.g., Fitzpatrick et al., 2013). Although several previous studies have mapped the locations of supraglacial streams (e.g., Colgan et al., 2011; McGrath et al., 2011; Yang and Smith, 2013) or the bathymetry of supraglacial lakes (e.g., Box and Ski, 2007; Sneed and Hamilton, 2007; Tedesco and Steiner, 2011) from optical image data, none have attempted to retrieve water depth in supraglacial streams.

Spectrally based methods of bathymetric mapping are well established in coastal environments, where decades of research have yielded insight on the radiative transfer processes governing the interaction of light and water (e.g., Lyzenga, 1978; Philpot, 1989; Maritorena et al., 1994). In addition to depth, the reflectance from a water body depends on the optical properties of the water column and the albedo of the bottom. Tedesco and Steiner (2011) quantified these two parameters by collecting field measurements of depth and reflectance from a supraglacial lake on the GrIS; these data were also used to relate bathymetry to spectral reflectance for individual bands of the Landsat 7 (ETM+) and Moderate Resolution Imaging Spectroradiometer (MODIS) satellites. A related study used in situ observations of depth and optical properties from a melt pond to verify the underlying assumptions of the Sneed and Hamilton (2007) depth retrieval algorithm: negligible amounts of sediment or organic matter; a water surface undisturbed by waves; a lack of inelastic scattering; a flat, homogeneous substrate; and optically deep water (e.g., from the ocean) for estimating the volume reflectance of the water column. Field data supported the first three assumptions, while the role of substrate heterogeneity was ambiguous and deep-water observations were shown to be unnecessary; the analysis confirmed the validity of estimating melt pond depth via remote sensing (Sneed and Hamilton, 2011). Similarly, Fitzpatrick et al. (2013) used echo sounding, along with topographic surveys of a drained supraglacial lake, to calibrate reflectance values extracted from MODIS image pixels to depth. The resulting equation was applied to water-classified pixels to yield depth estimates, which were then integrated over the supraglacial lake area to calculate water storage volumes.

Although these early studies were encouraging, previous research also identified a number of issues and limitations that must be addressed. For example, Tedesco and Steiner (2011) showed that bathymetry inferred from satellite images could be sensitive to variations in bottom reflectance and/or water column optical properties. Sneed and Hamilton (2011) also identified substrate heterogeneity (e.g., cryconite patches) as a potential complicating factor in passive optical depth retrieval. Moreover, the coarser spatial resolutions of other satellites such as Landsat 7 (30 m), MODIS (250 m), and the Advanced Spaceborne Thermal Emission and Reflection Radiometer (ASTER, $15 \mathrm{~m}$ ) are too coarse for depth estimates along lake margins and can produce biased results due to the presence of ice within mixed pixels. Larger pixel sizes, particularly for the widely used MODIS instrument, also restrict bathymetric mapping to relatively large supraglacial lakes and precludes analysis of the streams that deliver meltwater into the ice sheet via moulins. Also, aside from the observations of Sneed and Hamilton (2011) and Tedesco and Steiner (2011) on lakes up to $3.0 \mathrm{~m}$ and $4.5 \mathrm{~m}$ deep, respectively, coincident in situ measurements of depth and reflectance for validating spaceborne bathymetry are lacking. Modeling studies provide an alternative means of estimating water storage volumes (e.g., Luthje et al., 2006; Leeson et al., 2012), but this approach is subject to various uncertainties as well (e.g., Tedesco et al., 2012).

This study addressed these shortcomings by applying spectrally based depth retrieval methods developed in shallow marine settings (e.g., Dierssen et al., 2003) and adapted to alluvial rivers (e.g., Legleiter and Overstreet, 2012) to the GrIS. More specifically, we evaluated the performance of a band ratio-based algorithm expected to be robust to variations in bottom albedo and water column optical properties (Stumpf et al., 2003; Legleiter et al., 2009). To assess the feasibility of this approach, we obtained concurrent, co-located field measurements of depth and reflectance in two meltwater streams and a large lake, with measured depths ranging 0.31$10.45 \mathrm{~m}$. Two WorldView2 (WV2) satellite images acquired within 3-72 h of our ground-based observations were used to assess the accuracy of image-derived depth estimates. Because WV2 provides higher spatial resolution ( $2 \mathrm{~m}$ pixels for multispectral data) relative to Landsat 7, MODIS, or ASTER, this sensor could help refine estimates of supraglacial storage by providing depth information from small lakes. In addition, WV2 data offer the possibility of mapping supraglacial streams, which represent not just a static storage volume but rather a transient flux conveying meltwater to moulins.

Ultimately, we seek to support development of a flexible, spectrally based approach to mapping the bathymetry of supraglacial lakes and streams that can serve as a central component of integrated workflows for characterizing the hydrology of the GrIS. Our investigation was motivated by the following objectives, which serve to organize the paper: 


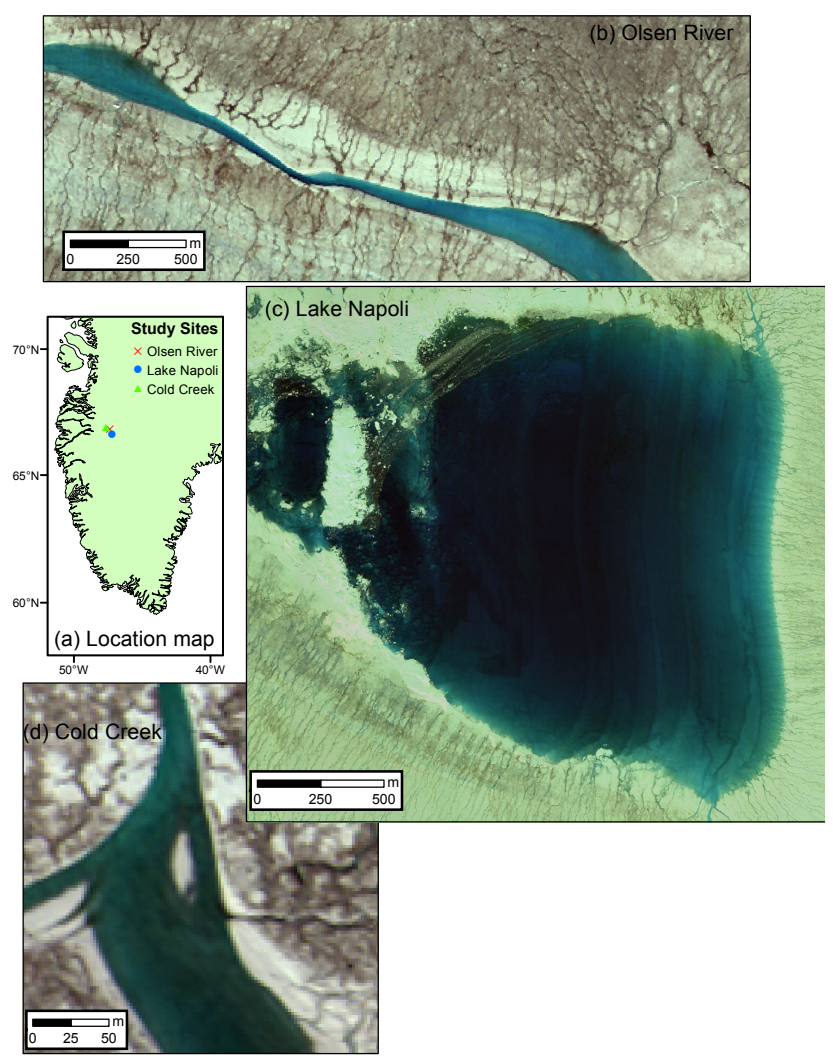

Fig. 1. Map (a) indicating the location of study area in southwestern Greenland. WorldView2 images of three primary field sites: (b) Olsen River, (c) Lake Napoli, and (d) Cold Creek. See Table 1 for more information on each site.

1. Use field spectra and depth measurements from the surface of the GrIS to assess the feasibility of spectrally based bathymetric mapping of supraglacial lakes and streams.

2. Develop robust algorithms for retrieving depth information, and hence water storage volumes and fluxes, from high-resolution satellite image data.

3. Assess the accuracy of image-derived depth estimates and identify the potential limitations associated with this approach.

\section{Methods}

\subsection{Study area}

Our study area was located in a portion of the ablation zone in southwestern Greenland (Fig. 1a) that generally features numerous supraglacial lakes and streams during the summer melt season. Field data and satellite images were acquired from three primary field sites described in Table 1 . The first stream we sampled, referred to as the Olsen River, consisted

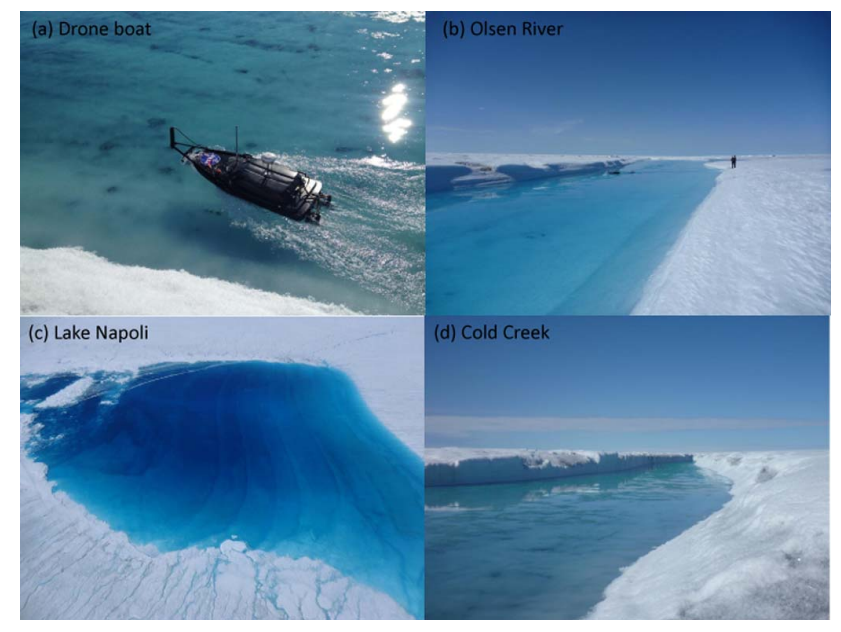

Fig. 2. Photographs of field sites on the surface of the Greenland ice sheet. (a) Remote-controlled drone boat used to collect simultaneous measurements of depth and reflectance, shown here along the Olsen River. (b) Olsen River, looking downstream toward the ice bar where the channel curves to the right. (c) Overview of Lake Napoli, taken from a helicopter, showing wave-cut platforms associated with former shorelines on the up-glacier (left) side of the lake. (d) Cold Creek, looking downstream.

of a broad, shallow channel where meltwater exited a lake transitioning to a narrower, deeper morphology confined by high banks of ice (Fig. 1b, 2a). The channel also featured a curve around an "ice bar", shown in Fig. 2b, analogous to the point bars found along meandering terrestrial rivers. Our second site, referred to as Lake Napoli, was roughly circular in shape, with an area of $3.05 \times 10^{6} \mathrm{~m}^{2}$ and a maximum measured depth of $10.45 \mathrm{~m}$. A series of parallel, northsouth trending ridges evident on the lakebed in a WV2 scene (Fig. 1c) were interpreted as wave-cut platforms associated with former shorelines on the east (up-glacier) side of the lake (Fig. 2c). The western shore of the lake was more irregular, with a complex bottom topography. Our final sampling location, referred to as Cold Creek (Fig. 1d), was a shallow, wide, slow-flowing outlet channel from a small lake; several mid-channel ice bars were present in this stream.

\subsection{Field data collection and analysis}

Field observations from these three supraglacial water bodies were obtained using a small, unmanned boat similar to that employed by Tedesco and Steiner (2011) but with a number of significant upgrades. The new motorized drone boat, a specially customized Oceanscience Z-Boat 1800 (Fig. 2a), was operated from shore via a remote control, which ensured safety of personnel in case of a sudden drainage event. This platform was small enough to fit inside a helicopter for transport onto the ice sheet but large enough to accommodate the instrument payload. Designed as a hydrographic survey vessel, the drone boat could be operated at up to $1 \mathrm{~km}$ distance 
Table 1. Study sites on the surface of the Greenland ice sheet (GrIS) from which field-based measurements of depth and reflectance and WorldView2 satellite images were acquired.

\begin{tabular}{|c|c|c|c|c|c|c|c|c|}
\hline Site & $\begin{array}{l}\text { Latitude } \\
\text { Longitude } \\
\text { Elevation } \\
\text { (m a.s.l.) }\end{array}$ & $\begin{array}{l}\text { Meltwater } \\
\text { surface } \\
\text { area }\left(\mathrm{m}^{2}\right)\end{array}$ & $\begin{array}{l}\text { Mean } \\
\text { channel } \\
\text { width } \\
\text { (m) }\end{array}$ & $\begin{array}{l}\text { Number } \\
\text { of field } \\
\text { data }\end{array}$ & $\begin{array}{l}\text { Mean } \\
\text { depth } \\
\text { (m) }\end{array}$ & $\begin{array}{l}\text { Max } \\
\text { depth } \\
\text { (m) }\end{array}$ & $\begin{array}{l}\text { Field data } \\
\text { collection }\end{array}$ & $\begin{array}{l}\text { Image } \\
\text { acquisition }\end{array}$ \\
\hline $\begin{array}{l}\text { Olsen } \\
\text { River }\end{array}$ & $\begin{array}{l}67^{\circ} 7^{\prime} 5.7^{\prime \prime} \\
-48^{\circ} 19^{\prime} 19.3^{\prime \prime} \\
1504\end{array}$ & 30785 & 32.3 & 3264 & 1.08 & 3.16 & $7 / 20 / 2012$ & $7 / 18 / 2012$ \\
\hline $\begin{array}{l}\text { Lake } \\
\text { Napoli }\end{array}$ & $\begin{array}{l}66^{\circ} 54^{\prime} 9.0^{\prime \prime} \\
-48^{\circ} 6^{\prime} 2.7^{\prime \prime} \\
1589\end{array}$ & 3048258 & $\mathrm{n} / \mathrm{a}$ & 4383 & 4.53 & 10.45 & $7 / 21 / 2012$ & $7 / 18 / 2012$ \\
\hline $\begin{array}{l}\text { Cold } \\
\text { Creek }\end{array}$ & $\begin{array}{l}67^{\circ} 10^{\prime} 49.5^{\prime \prime} \\
-48^{\circ} 45^{\prime} 53.5^{\prime \prime} \\
1335\end{array}$ & 14155 & 67.5 & 1164 & 0.93 & 1.66 & $7 / 23 / 2012$ & $7 / 23 / 2012$ \\
\hline
\end{tabular}

from the remote control, and the rechargeable battery system provided sufficient power for deployments up to several hours in duration. Maneuverability of the boat was defined by maximum speeds of 4-5 $\mathrm{m} \mathrm{s}^{-1}$ and minimum turning radius of $4 \mathrm{~m}$. Owing to the potential interference of the boat's hull with spectral measurements, the plastic hull was given a special flat black finish to minimize reflectance. Measurement locations were determined using a Trimble R8 GPS mounted on the boat. The GPS data collector also communicated with an Ohmex SonarMite $235 \mathrm{KHz}$ echo sounder that measured water depths with an accuracy of $\pm 0.025 \mathrm{~m}$ at a sampling frequency of $1 \mathrm{~Hz}$. Because the drone boat was driven at low velocities $\left(\sim 1 \mathrm{~m} \mathrm{~s}^{-1}\right)$, this system provided very dense bathymetric coverage.

Measurements of upwelling spectral radiance $L_{\mathrm{u}}(\lambda)$ at each wavelength $\lambda$ were made using an Analytical Spectral Devices (ASD) FieldSpec3 spectroradiometer with a spectral sampling interval of $1 \mathrm{~nm}$ for visible and near-infrared (NIR) wavelengths from 350 to $1025 \mathrm{~nm}$; only data from 400 to $900 \mathrm{~nm}$ were considered due to low signal-to-noise outside this range (Tedesco and Steiner, 2011). The instrument was secured inside the boat's watertight hull and connected via fiber optic cable to a fore optic with a $5^{\circ}$ field of view mounted on a boom extending ahead of the boat to minimize self-shading effects. We attempted to navigate so as to avoid configurations for which the boat might cast a shadow within the field of view of the spectroradiometer, but in a small number of cases shadows could not be avoided. The fore optic was placed immediately above the water surface and pointed downward to ensure a consistent nadir-viewing geometry. Our sampling strategy thus differed from that of Tedesco and Steiner (2011), who made reflectance measurements underwater to avoid the confounding effects of reflectance from and transmittance through the air-water interface. In this study, we reasoned that because remotely sensed data also are subject to these effects, field spectra recorded from above the water surface would provide a more direct means of as- sessing the potential for mapping bathymetry from satellite images. The boat-based spectroradiometer was re-calibrated periodically during each deployment by pointing the fore optic at a Spectralon reference panel, which served to set the integration time, account for the instrument's dark current, and establish the conversion from raw digital counts to spectral radiance units.

A simultaneous time series of downwelling spectral irradiance $E_{\mathrm{d}}(\lambda)$ was recorded on shore by an ASD HandHeld2 spectroradiometer. This instrument was located within $400 \mathrm{~m}$ of all boat-based measurements from Olsen River and Cold Creek and within $800 \mathrm{~m}$ of the boat on Lake Napoli. Over these sub-kilometer distances, differences in solar zenith angle between the shore- and boat-based sensors were negligible. To capture incoming radiation from throughout the upper hemisphere, the on-shore spectroradiometer was equipped with a cosine receptor oriented skyward. Data from the boatand shore-based ASD's were synchronized and remote sensing reflectance $R_{\mathrm{rS}}(\lambda)$ calculated as the ratio of $L_{\mathrm{u}}(\lambda)$ measured on the boat to $E_{\mathrm{d}}(\lambda)$ recorded on shore. Reflectance $R(\lambda)$ was obtained by multiplying $R_{\mathrm{rs}}$ by $\pi$, assuming a Lambertian bidirectional reflectance distribution function. Time stamps were used to pair these reflectance data with the depth measurements and GPS positions.

\subsection{Image data acquisition and processing}

To assess the potential for spaceborne mapping of supraglacial bathymetry, we examined two WV2 satellite images. This sensor provides higher spatial and spectral resolution than more widely used platforms such as Landsat 7 (ETM+), MODIS, or ASTER with $2 \mathrm{~m}$ pixels for each of eight spectral bands. In addition to standard blue, green, red, and NIR bands, WV2 includes coastal (400-450 nm), yellow $(585-625 \mathrm{~nm})$, and red edge $(705-745 \mathrm{~nm})$ bands that were expected to be useful for depth retrieval from shallow meltwater streams. WV2's longest wavelength band 
(860-1040 nm) might be helpful for discriminating water from ice along lake and channel margins but was excluded from the depth retrieval analysis because strong absorption by pure water in this portion of the spectrum implies small $L_{\mathrm{u}}(\lambda)$ values and poor signal-to-noise for water pixels, particularly in deeper areas.

WV2 images from our study sites were acquired on 18 and 23 July 2012, within 3-72 h of field data collection (Table 1). Images were orthorectified and projected to a polar stereographic coordinate system using a code developed by the Polar Geospatial Center at the University of Minnesota. Radiometric coefficients for each band were included in the WV2 metadata and used to convert raw digital counts to radiance. Atmospheric correction was performed using the Fast Line-of-sight Atmospheric Analysis of Spectral Hypercubes (FLAASH) algorithm based on the MODTRAN4 radiation transfer code (Adler-Golden et al., 1999). Inputs to FLAASH included the radiance image, scene date and location, ground elevation and sensor altitude, spectral band configuration, visibility $(40 \mathrm{~km})$, and standard models for the atmosphere (sub-arctic summer) and aerosols (rural). By performing a series of iterative calculations to estimate column water vapor, FLAASH generated atmospherically corrected images in units of apparent surface reflectance $R(\lambda)$.

Linking specific pixels from these images to individual field measurements required precise spatial referencing of the remotely sensed data. Orthorectification of the WV2 images for our Lake Napoli and Cold Creek sites was highly accurate, with all of our boat-based field measurements plotting within the water bodies depicted in the scene. For the Olsen River, however, the initial geo-referencing was in error by several meters, with many of our field data located outside the stream on the image. To refine the spatial referencing, we manually digitized a channel polygon on the image and compared this feature to a polygon enveloping the field data. An iterative transformation procedure described by Legleiter (2012) was then used to shift the image into alignment with our field observations.

To isolate the meltwater present in each image, we created masks based on NIR reflectance thresholds. The longest wavelength NIR band was displayed as a grayscale image and the contrast stretch adjusted interactively to identify an appropriate cutoff value for distinguishing water from ice. The initial threshold-based mask was refined through morphological opening, segmentation, and closing (Legleiter et al., 2011). The resulting masks were applied to the reflectance images and a $3 \times 3$ pixel Wiener filter used to smooth the in-stream portion of each scene (Legleiter, 2013).

\subsection{Spectrally based depth retrieval}

Quantitative relationships between water depth $d$ and spectral reflectance $R(\lambda)$ provide a basis for mapping supraglacial bathymetry from passive optical image data. Although the upwelling radiance recorded by a remote detector also is influenced by several other factors, the effect of depth can be isolated using measurements from multiple spectral bands. More specifically, under appropriate conditions, outlined below, and for certain combinations of wavelengths, the image-derived quantity

$X=\ln \left[\frac{R\left(\lambda_{1}\right)}{R\left(\lambda_{2}\right)}\right]$

is linearly related to depth. The physical principles underlying depth retrieval via band ratios were described, for example, by Dierssen et al. (2003) for coastal settings and Legleiter et al. (2004, 2009) for gravel-bed rivers; the premise of this study is that similar radiative transfer processes operate in the supraglacial environment as well.

To summarize, the total radiance $L_{\mathrm{T}}(\lambda)$ measured above an optically shallow water body is the sum of contributions from the bottom, water column, water surface, and atmosphere. Of these components, only the radiance reflected from the bottom $L_{\mathrm{B}}(\lambda)$ is directly related to depth. $L_{\mathrm{B}}(\lambda)$ also depends on the reflectance $R_{\mathrm{b}}(\lambda)$ of the bottom itself, but for an appropriate pair of bands the ratio $R_{\mathrm{b}}\left(\lambda_{1}\right) / R_{\mathrm{b}}\left(\lambda_{2}\right)$ tends to be nearly constant across bottom types. Moreover, spectral differences in $R_{\mathrm{b}}(\lambda)$ for a given substrate are small, on the order of a few percent, relative to the orderof-magnitude increase in attenuation by the water column as wavelength increases from the blue into NIR. The transfer of radiant energy through the water column is controlled by various absorption and scattering processes that impart a color, or volume reflectance, $R_{\mathrm{c}}(\lambda)$, to the water itself; these processes are summarized in terms of an effective attenuation coefficient, $K(\lambda)$. In clear water free from high concentrations of suspended sediment or organic material, $K(\lambda)$ is driven primarily by absorption by pure water (Legleiter et al., 2009). Analysis of water samples collected from an East Greenland melt pond by Sneed and Hamilton (2011) confirmed that suspended or dissolved, organic or inorganic, particulate matter was minimal and had no significant influence on radiative transfer within the water column.

Legleiter et al. (2009) presented a scaling argument that in shallow, clear water bodies with highly reflective substrates, $L_{\mathrm{T}}(\lambda)$ is dominated by $L_{\mathrm{b}}(\lambda)$ and the other radiance components can be considered negligible. Beginning from an expression for $L_{\mathrm{T}}(\lambda)$ presented by Philpot (1989), Legleiter et al. (2009) showed that under these circumstances the logarithm of the ratio of the radiances (or, equivalently, reflectances since $R=\pi L_{\mathrm{T}} / E_{\mathrm{D}}$ ) measured in two spectral bands, denoted by numeric subscripts, can be simplified to yield a linear equation relating the radiometric quantity $X$ to the water depth $d$ :

$X=\ln \left[\frac{L_{\mathrm{T} 1}}{L_{\mathrm{T} 2}}\right] \approx\left(K_{2}-K_{1}\right) d+\ln \left[\frac{\left(R_{\mathrm{b} 1}-R_{\mathrm{c} 1}\right)}{\left(R_{\mathrm{b} 2}-R_{\mathrm{c} 2}\right)}\right]+A$,

where the dependence on wavelength of all quantities except for depth has been suppressed for clarity. The slope term in 
this equation depends on the difference in attenuation between the two bands; $X$ increases with depth for $K_{2}>K_{1}$ because the radiance in the more strongly absorbing band $\lambda_{2}$ decreases more rapidly as depth increases than does $L_{\mathrm{T} 1}$. The intercept term accounts for the "bottom contrast" $R_{\mathrm{b}}-R_{\mathrm{c}}$ between the substrate and water column as well as a constant $A$ that depends on the downwelling spectral irradiance $E_{\mathrm{D}}(\lambda)$ and transmission across the air-water interface and through the atmosphere. If the optical properties of the water column remain uniform throughout the lake or stream reach, the only quantity in Eq. (2) expected to vary spatially on a pixel-bypixel basis is the one of interest, $d$; the remotely sensed variable $X$ is thus well suited for bathymetric mapping (Legleiter et al., 2009).

Depth retrieval via this method involves identifying an appropriate pair of wavelengths and calibrating a relation between $d$ and $X$. A technique called optimal band ratio analysis, or OBRA (Legleiter et al., 2009), accomplishes both of these objectives by performing regressions of $d$ on $X$ for all possible combinations of numerator $\lambda_{1}$ and denominator $\lambda_{2}$ bands. The optimal band ratio is the one yielding the highest $R^{2}$, with the corresponding regression equation serving to calibrate $X$ values to depth. Because regressions are performed for all possible pairs of wavelengths, OBRA also allows spectral variations in the strength of the $d$ vs. $X$ relationship to be visualized as a matrix of $R^{2}\left(\lambda_{1}, \lambda_{2}\right)$ values.

We conducted OBRA for both field spectra recorded from the boat and image spectra from the WV2 satellite. For the field spectra, we used depths measured by the echo sounder at the same time as the reflectance data. To assess the feasibility of retrieving depth from multispectral image data with relatively broad bands, we also convolved the original field spectra, sampled every $1 \mathrm{~nm}$, with the spectral response functions of WV2, Landsat 7, MODIS, and ASTER and repeated the OBRA for the convolved spectra. Although this study focused on WV2 images, conducting OBRA for the other, more widely used sensors provided a means of assessing whether strong depth-reflectance relations could be obtained from coarser spectral resolution data. For OBRA of the WV2 image spectra, all depth measurements located within a given pixel were averaged and a mean depth assigned to the pixel center. Reflectance spectra for the field data locations were then extracted from the masked, filtered WV2 image and used as input to OBRA. Because Lake Napoli featured depths over $10 \mathrm{~m}$, we also performed a quadratic version of OBRA that included both $X$ and $X^{2}$ terms in each regression; Dierssen et al. (2003) found that such a quadratic formulation provided more accurate depth estimates in deeper areas.

Linear and quadratic OBRA were performed for the original and convolved field spectra and for the WV2 image spectra for each site individually and for a merged data set aggregated across all three sites. For the merged field data set and each of the images, calibration relationships were derived from a randomly selected subset $(50 \%)$ of the reflectance spectra and collocated depth measurements. The other half of each data set was retained and used to assess the accuracy of image-derived depth estimates in terms of mean error, root mean square errors (RMSE), and regression of observed (field-based) vs. predicted (image-derived) depths (Pineiro et al., 2008). In addition, we applied OBRA relations to the WV2 images to produce bathymetric maps, which were inspected for realistic spatial patterns and general agreement with our field observations.

\section{Results}

\subsection{Depth-reflectance relations from field spectra}

To assess the feasibility of inferring the depth of supraglacial water bodies from their spectral characteristics, we used field measurements of depth and reflectance to perform OBRA for each field site individually and for a merged data set (Table 2). Moderately strong $X$ vs. $d$ relations were observed for both streams, but correlations between band ratio values and water depth were much greater for Lake Napoli and the merged data set. The weaker OBRA relations for the streams could in part be a consequence of the limited range of depths measured in these shallow channels $(0.31-$ $4.45 \mathrm{~m})$, particularly Cold Creek $(0.31-1.69 \mathrm{~m})$, whereas the Lake Napoli and merged data sets encompassed depth observations up to $10.45 \mathrm{~m}$. In addition, reflectance spectra from the streams might have been influenced to a greater degree by factors other than depth, including the localized effects of cryconite substrates with darker bottom albedo, cracks in the ice bed, variable water surface roughness, shadows, and floating pieces of slush.

For all three sites, the numerator and denominator wavelengths identified via linear OBRA were very close to one another, implying that the greatest sensitivity to depth occurred in narrow portions of the spectrum, ranging from $580 \mathrm{~nm}$ for Lake Napoli to $660 \mathrm{~nm}$ for the Olsen River. Inspection of the OBRA matrices shown in Fig. 3, however, indicated that a broader range of wavelengths throughout the visible portion of the spectrum would provide $X$ vs. $d$ relations nearly as strong as the optimal band ratios. For the Olsen River and Cold Creek, blue and green wavelengths less than $550 \mathrm{~nm}$ were of limited value as denominator bands due to efficient penetration of light through water in these bands. In these shallow channels, changes in depth translated into only small changes in reflectance in this portion of the spectrum, whereas stronger absorption of red and NIR light resulted in greater decreases in reflectance for a given increase in depth. Conversely, greater depths in Lake Napoli dictated that shorter wavelengths capable of penetrating to the bottom were more useful than red and NIR bands in which the radiance signal saturated due to nearly complete absorption in deeper water.

For the merged data set comprised of observations from shallow streams as well as deeper areas of the lake, the 
Table 2. Summary of optimal band ratio analysis (OBRA) of field spectra and depth measurements from three field sites on the surface of the GrIS and for the merged data set aggregated over the three sites.

\begin{tabular}{llllllllrr}
\hline Site & $\begin{array}{l}\text { Calibration } \\
\text { data } \\
\text { (count) }\end{array}$ & $\begin{array}{l}\text { Spectrum } \\
\text { type }^{\mathrm{a}}\end{array}$ & Sensor & $\begin{array}{l}\text { OBRA } \\
\text { type }\end{array}$ & $\begin{array}{l}\text { OBRA } \\
R^{2}\end{array}$ & $\lambda_{1}^{\mathrm{c}}$ & $\lambda_{2}^{\mathrm{d}}$ & $\mathrm{SE}^{\mathrm{e}}$ & $\mathrm{SE}^{\mathrm{b}}$ \\
\hline Olsen River & 2371 & Cont. & ASD & Linear & 0.80 & 655 & 659 & 0.30 & 28 \\
Cold Creek & 781 & Cont. & ASD & Linear & 0.61 & 593 & 594 & 0.16 & 18 \\
Lake Napoli & 2424 & Cont. & ASD & Linear & 0.90 & 581 & 582 & 0.38 & 8 \\
Merged & $2788 \mathrm{~g}$ & Cont. & ASD & Linear & 0.92 & 583 & 604 & 0.47 & 31 \\
& & Cont. & ASD & Quad. & 0.94 & 584 & 599 & 0.43 & 29 \\
& & Conv. & WV2 & Linear & 0.89 & 545 & 605 & 0.55 & 37 \\
& & Conv. & WV2 & Quad. & 0.92 & 545 & 605 & 0.49 & 33 \\
& & Conv. & Landsat & Linear & 0.85 & 499 & 669 & 0.65 & 43 \\
& & Conv. & Landsat & Quad. & 0.88 & 499 & 669 & 0.60 & 40 \\
& & Conv. & MODIS & Linear & 0.88 & 550 & 658 & 0.60 & 40 \\
& & Conv. & MODIS & Quad. & 0.89 & 550 & 658 & 0.56 & 37 \\
& & Conv. & ASTER & Linear & 0.86 & 531 & 638 & 0.65 & 43 \\
& & Conv. & ASTER & Quad. & 0.87 & 531 & 638 & 0.61 & 41 \\
\hline
\end{tabular}

a Cont.: continuous field spectra, or Conv.: field spectra convolved to sensor bands.

${ }^{\mathrm{b}}$ Linear or quadratic formulation of OBRA.

c $\lambda_{1}$ : numerator wavelength for optimal band ratio.

$\mathrm{d} \lambda_{2}$ : denominator wavelength for optimal band ratio.

e Regression standard error for optimal band ratio.

f Analytical Spectral Devices spectroradiometer used to measure field spectra.

$\mathrm{g}$ For merged data set, half of the data were used for calibration and half reserved for validation.

h More specifically, "Landsat" refers to the Landsat 7 (ETM+) sensor.

addition of a quadratic term to the OBRA formulation produced a marginal improvement in the strength of the $X$ vs. $d$ relation $\left(R^{2}=0.94\right)$. In this case, a pair of wavelengths in the yellow portion of the spectrum, 584 and $599 \mathrm{~nm}$, were identified as optimal, but the OBRA matrix in Fig. 3d indicated that many other band combinations had $R^{2}$ values nearly as high; $\lambda_{1}<600 \mathrm{~nm}$ yielded strong correlations between $X$ and $d$ when paired with $470<\lambda_{2}<720 \mathrm{~nm}$.

These results suggested that broader wavelength bands, as opposed to essentially continuous field spectra, would be sufficient for depth retrieval. To test this possibility, we convolved the field spectra from the merged data set to match the spectral response functions of the WV2, Landsat 7, MODIS, and ASTER sensors and performed OBRA of the convolved spectra. For all four sensors and for both the linear and quadratic formulations of OBRA, the reduced spectral resolution resulted in only a slight decrease in the strength of the relationship between $X$ and $d$ (Table 2 and Fig. 4). The WV2 sensor's green and yellow bands were optimal, consistent with the wavelengths selected from the original field spectra. Even for the Landsat 7, MODIS, and ASTER sensors having only three or four visible/NIR bands, the OBRA $R^{2}$ values were nearly as high as for the 7-band WV2 system. Figure 4 indicates that for the latter three instruments, defining $X$ using green and red bands yielded the strongest linear relations with depth. These results imply that multispectral imaging systems, including Landsat 7, MODIS, and ASTER as well as WV2, have adequate spectral resolution for bathy- metric mapping. Because the OBRA $R^{2}$ values for all three sensors were similar, the primary advantage of WV2 would be enhanced spatial resolution, but our results indicate that robust depth-reflectance relations can be derived for Landsat 7, MODIS, and ASTER data as well. Although these sensors have coarser pixel sizes that would restrict analysis to larger water bodies, the broader spatial and more frequent temporal coverage of Landsat 7 and MODIS make them useful for scaling up and examining more extensive areas of the GrIS over longer time periods. Irrespective of the remote sensing system employed, our field measurements of depth and reflectance provided direct, on-the-ground evidence confirming the feasibility of spectrally based depth retrieval from supraglacial water bodies.

\subsection{Mapping supraglacial bathymetry from satellite image data}

To more directly evaluate whether reliable depth information could be inferred from passive optical image data, we coupled field measurements of depth with spectra extracted from two WV2 images that were acquired within 3-72 h of field data collection. Table 3 and Fig. 6 summarize the results of linear and quadratic OBRA performed for each site individually and for a merged data set aggregated across the three sites. Strong to very strong relationships between the image-derived quantity $X$ and water depth $d$ were observed in all cases, with OBRA $R^{2}$ values ranging from 0.79 to 

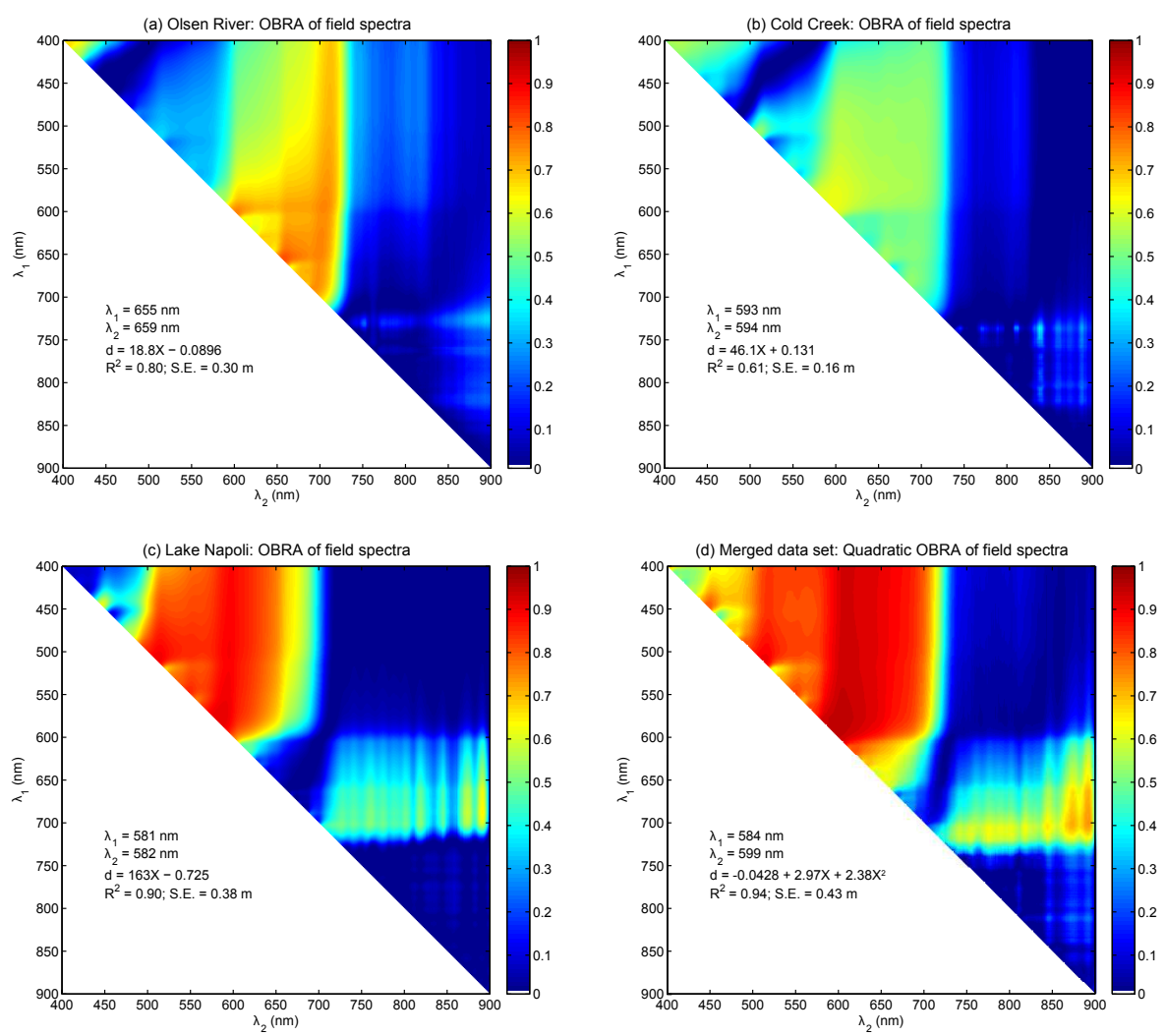

Fig. 3. Optimal band ratio analysis (OBRA) of field spectra for each study site and for a merged data set aggregated across the three sites.

0.93. Accuracy assessment involved applying OBRA regression equations to a validation sub-sample of each data set. The difference between field-measured and image-derived depths was less than $1 \%$ of the mean depth in all cases, indicating that depth estimates were unbiased on average. Small root mean square errors, ranging from 10 to $26 \%$ of the mean depth for each site, implied that depth estimates were precise as well. Similarly, regressions of observed vs. predicted depths showed that remote bathymetric mapping of supraglacial lakes and streams was accurate, with $R^{2}$ values from 0.78 to 0.93 . Moreover, OP regression intercept and slope coefficients near 0 and 1 , respectively, indicated that image-derived depths were not subject to any kind of systematic bias. The results of our depth retrieval accuracy assessment compare favorably to those reported by Fitzpatrick et al. (2013). In that study, a depth-reflectance relation based on a single MODIS band yielded an OP regression $R^{2}$ value of 0.79 and a typical error of $1.47 \mathrm{~m}$ for four lakes with depths up to $12 \mathrm{~m}$.

For the individual sites, linear OBRA yielded $R^{2}$ values nearly as high as the quadratic version of the algorithm, implying that the addition of an $X^{2}$ term was not necessary on a site-by-site basis. For the merged data set, however, the broader range of field-measured depths, including some in excess of $10 \mathrm{~m}$, introduced mild curvature to the relation between $X$ and $d$ (Fig. 5a); a quadratic function thus pro- vided a better overall fit. Introducing an $X^{2}$ term prevented negative depth estimates in shallow water, a common problem in terrestrial rivers (Legleiter et al., 2009), and severe under-prediction of depth in deeper areas. Validation of the quadratic OBRA relation for the merged data set via the OP regression shown in Fig. 5b showed good overall agreement between observed and predicted depths $\left(R^{2}=0.93\right)$ but considerable scatter about the 1-to-1 line, with a tendency to underestimate the greatest depths. The distinct clustering of points from the Olsen River vs. Cold Creek on both the calibration and validation plots in Fig. 5 was due at least in part to the location of the two streams on different WV2 images, which were processed separately to units of apparent surface reflectance. Because these sites were located on separate images and the majority of the merged data set was drawn from the deeper waters of Lake Napoli, the quadratic OBRA relation based on data from all three sites yielded low OP $R^{2}$ values when applied to the data from each individual stream: 0.25 for the Olsen River and 0.14 for Cold Creek. Applying the merged relation to the data from Lake Napoli alone resulted in a much higher OP $R^{2}$ of 0.90 .

A potentially important advantage of OBRA relative to other depth retrieval approaches that are based on individual bands is an explicit focus on spectral variations in the nature and strength of the relationship between the image-derived quantity $X$ and water depth. The information present in the 

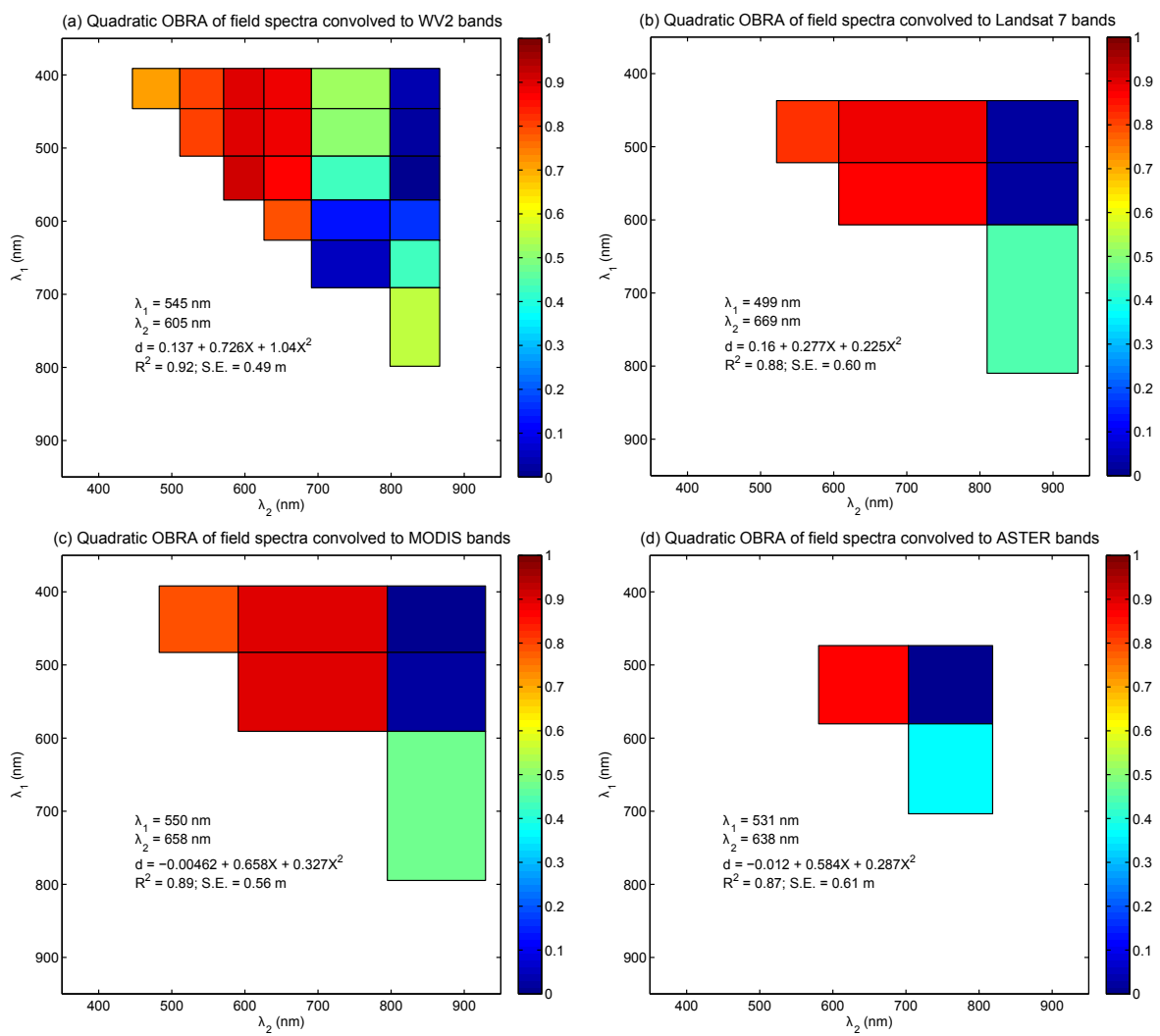

Fig. 4. Quadratic optimal band ratio analysis (OBRA) of field spectra aggregated across the three sites and convolved to the sensor bands for (a) WV2, (b) Landsat 7, (c) MODIS, and (d) ASTER.

OBRA matrices shown in Fig. 6, for example, can help to guide selection of an appropriate combination of bands. For our data from the GrIS, a different set of bands was identified as optimal for each site and for the merged data set (Table 3). Moreover, the OBRA matrices showed that the number of bands useful for depth retrieval and the utility of specific bands varied appreciably among data sets.

For the Olsen River the red / NIR ratio was optimal but was associated with an $X$ vs. $d$ relation with a negative slope, whereas a positive relation was expected. The selection of a NIR band also was not anticipated due to strong absorption of these wavelengths by pure water. In this case, both the strong correlation with NIR reflectance and the negative slope of the $X$ vs. $d$ relation can be explained in terms of adjacency effects. The presence of bright ice next to dark water, scattering by the atmosphere, and mixed, $2 \mathrm{~m}$ pixels representing a large fraction of the mean channel width all contributed to higher NIR reflectance near the banks, where depths were shallow. In the absence of such confounding effects, NIR reflectance would be much lower and would not vary significantly with changes in depth. In fact, OBRA of field spectra, which were less influenced by these pixel-scale, atmospheric issues, indicated that NIR wavelengths were not useful for depth retrieval. For image spectra subject to adja- cency effects, however, NIR reflectance acted as a proxy for distance from the bank and was thus correlated with depth.

For Cold Creek, the red edge and NIR bands did not yield high $X$ vs. $d$ regression $R^{2}$ values because most of our observations from this broad, shallow channel were collected farther from the banks. Because the Olsen River was much narrower, a greater proportion of pixels from that site were subject to adjacency effects, which were most pronounced in the NIR because reflectance from the water was lowest at these longer wavelengths. Figure $6 \mathrm{a}$ also indicates, however, that the blue/yellow band ratio would yield an $R^{2}$ value nearly as high and would be less influenced by adjacency effects.

Even for the larger Lake Napoli, the optimal band ratio included a NIR denominator and yielded a negative slope for the $X$ vs. $d$ relation, suggesting that for some images, such as that which included the Olsen River and Lake Napoli, adjacency effects associated with atmospheric scattering could be pervasive. For the merged data set pooled across the three field sites and two images, some NIR band combinations yielded moderate $R^{2}$ values, but the ratio of the WV2 sensor's coastal and green bands stood out as optimal, with a positive relation between $X$ and $d$ (Fig. 5a). Because these wavelengths penetrated more efficiently through the water, 

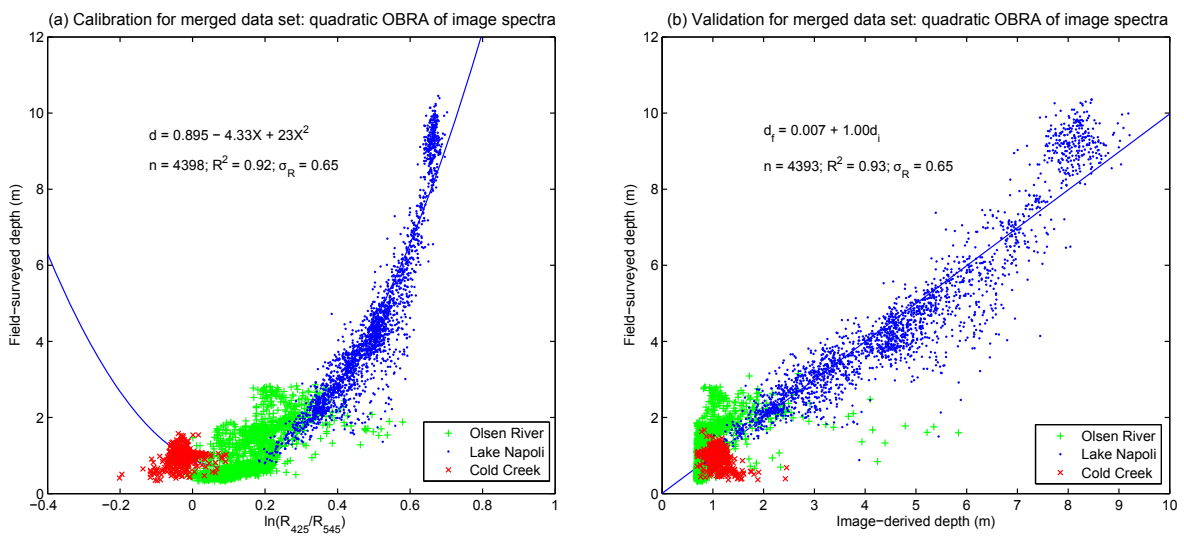

Fig. 5. (a) Calibration of the image-derived quantity $X$ to water depth for the merged data set drawn from all three field sites, distinguished by the symbols shown in the legend. (b) Validation of image-derived depth estimates via regression of observed vs. predicted depths for a subset of the merged data set.

Table 3. Accuracy assessment for depth retrieval from WV2 satellite images of supraglacial water bodies on the GrIS.

\begin{tabular}{lclrrrrrrrrrr}
\hline Site & $\begin{array}{c}\text { Calibration data } \\
(\text { count })\end{array}$ & $\begin{array}{l}\text { OBRA }^{\mathrm{a}} \\
\text { type }^{\mathrm{b}}\end{array}$ & $\begin{array}{r}\text { OBRA } \\
R^{2}\end{array}$ & $\begin{array}{r}\lambda_{1}^{\mathrm{c}} \\
(\mathrm{nm})\end{array}$ & $\begin{array}{r}\lambda_{2}^{\mathrm{d}} \\
(\mathrm{nm})\end{array}$ & $\begin{array}{r}\text { ME } \\
(\mathrm{m})\end{array}$ & $\begin{array}{r}\text { ME } \\
(\%)\end{array}$ & $\begin{array}{r}\text { RMSE } \\
(\mathrm{m})\end{array}$ & $\begin{array}{r}\text { RMSE } \\
(\%)\end{array}$ & $\begin{array}{r}\text { OP }^{\mathrm{e}} \\
R^{2}\end{array}$ & $\begin{array}{r}\text { OP int. }^{\mathrm{f}} \\
(\mathrm{m})\end{array}$ & $\begin{array}{r}\text { OP } \\
\text { slope }\end{array}$ \\
\hline Olsen & \multirow{2}{*}{1632} & Linear & 0.79 & 660 & 832 & 0.007 & 0.62 & 0.28 & 26 & 0.79 & 0.01 & 1.00 \\
River & & Quad. & 0.82 & 480 & 605 & 0.006 & 0.56 & 0.27 & 25 & 0.80 & 0.01 & 0.99 \\
Cold & \multirow{2}{*}{574} & Linear & 0.79 & 425 & 660 & -0.001 & -0.12 & 0.10 & 11 & 0.78 & 0.00 & 1.00 \\
Creek & & Quad. & 0.80 & 425 & 660 & -0.002 & -0.16 & 0.10 & 10 & 0.79 & -0.01 & 1.01 \\
Lake & \multirow{2}{*}{2192} & Linear & 0.91 & 545 & 725 & -0.031 & -0.67 & 0.73 & 16 & 0.90 & -0.01 & 1.00 \\
Napoli & & Quad. & 0.93 & 545 & 832 & -0.012 & -0.25 & 0.61 & 13 & 0.93 & -0.02 & 1.00 \\
Merged & \multirow{2}{*}{4398} & Linear & 0.75 & 425 & 545 & 0.023 & 0.80 & 1.17 & 42 & 0.77 & 0.01 & 1.01 \\
& & Quad. & 0.92 & 425 & 545 & -0.002 & -0.05 & 0.65 & 23 & 0.93 & 0.007 & 1.00 \\
\hline
\end{tabular}

a OBRA: optimal band ratio analysis.

$\mathrm{b}$ Linear or quadratic formulation of OBRA.

c $\lambda_{1}$ : numerator wavelength for optimal band ratio.

d $\lambda_{2}$ : denominator wavelength for optimal band ratio.

e OP: observed vs. predicted regression.

$\mathrm{f}$ int.: intercept of regression equation.

reflectances within the stream or lake were relatively high and more similar to the banks, making these bands less sensitive to adjacency effects.

By allowing for curvature in the $X$ vs. $d$ relation, quadratic OBRA could provide robust relationships less susceptible to these issues and more useful for depth retrieval. In addition to the quantitative accuracy assessment summarized above, we also inspected bathymetric maps produced by applying OBRA regression equations to the WV2 images. An example from the Olsen River is shown in Fig. 7, along with the field measurements used for calibration. For this site, the band ratio selected via linear OBRA, which included a NIR denominator, resulted in a noisy, speckled depth map due to low reflectance and thus poor signal-to-noise in the NIR band. Quadratic OBRA, in contrast, identified the blue/yellow band combination as optimal and resulted in a much smoother, spatially coherent bathymetric map. The red tones in Fig. 7 indicate shallow depths in the broad upper reach and over the ice bar where the channel curves to the right (Fig. 2b). The close-up in Fig. 7 also highlighted a deeper pool along the opposite bank just downstream of this bar, reminiscent of the bar-pool morphology common in terrestrial rivers. Similarly, a transect (Fig. 8a) across a straight segment of the Olsen River near the lower end of our study reach captured the gross, U-shaped morphology of the channel. Agreement between image-derived depths and field surveys was generally good for this cross section but the remotely sensed bathymetry was biased shallow and failed to detect a couple of small streambed irregularities evident in the field data. Nevertheless, our spectrally based approach, applied to highresolution images, appeared capable of providing detailed information on the depth and morphology of supraglacial streams. A second transect (Fig. 8b) drawn from Lake Napoli exhibited very close correspondence between field surveys and image-derived depths along a traverse from the shore toward the center of the lake that spanned a range of depths up 

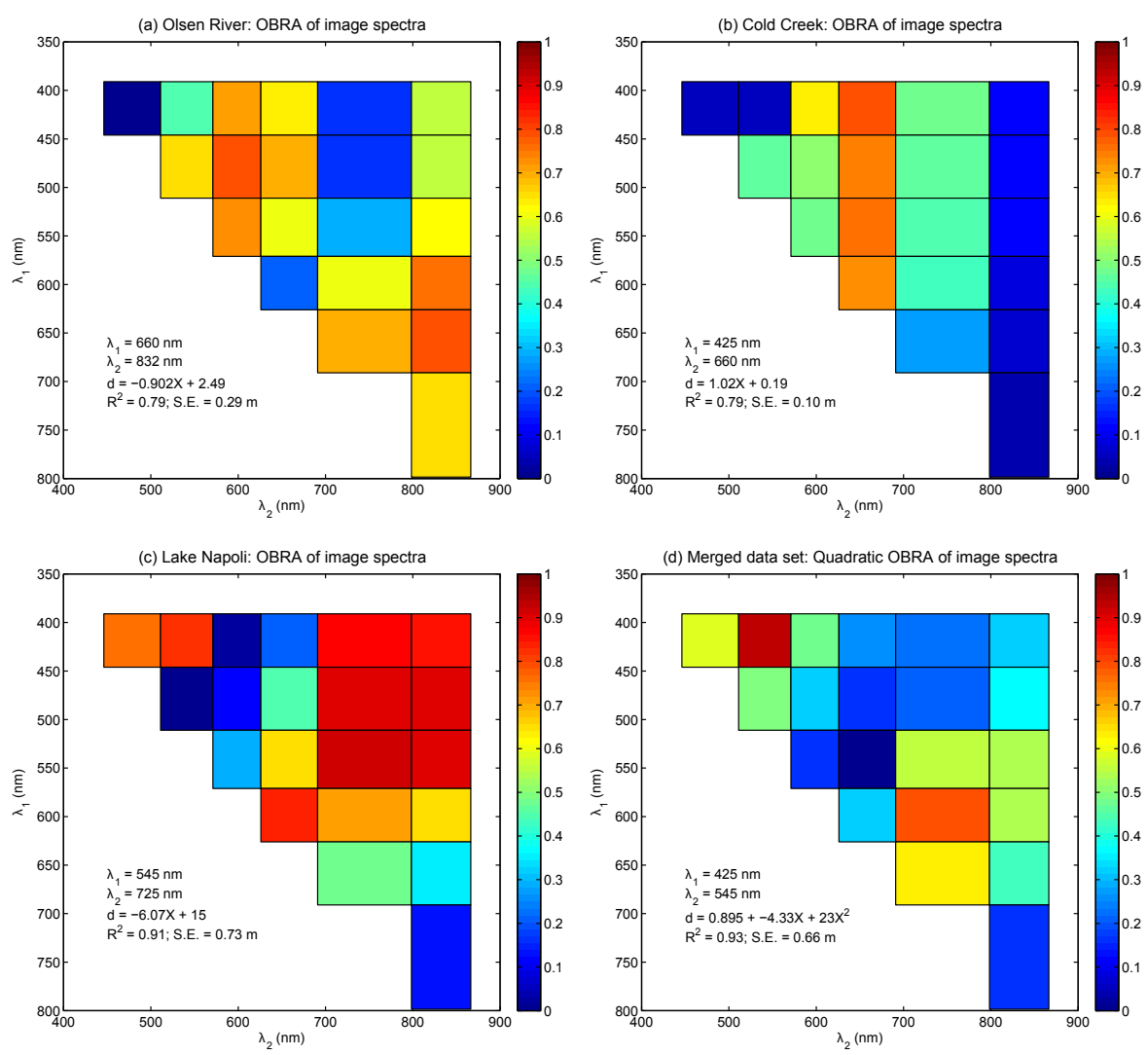

Fig. 6. OBRA of WV2 image spectra for each study site and for a merged data set aggregated across the three sites.

to $10 \mathrm{~m}$; these results indicated that accurate depth retrieval was possible in deeper melt ponds than reported in previous field studies (e.g., Tedesco and Steiner, 2011; Sneed and Hamilton, 2011; Fitzpatrick et al., 2013). The combination of improved spatial resolution and more reliable bathymetric information across a broader range of depths can thus enable refined estimates of meltwater storage volumes on the surface of the Greenland ice sheet.

\section{Discussion}

The volume, spatial distribution, and flux of meltwater on the surface of the ice sheet are important aspects of Greenland's hydrologic system. Improved methods of characterizing these components could thus help to constrain estimates of the contribution of the GrIS to sea level rise. In this study, we evaluated the potential to retrieve information on water depth, and hence storage volumes, in supraglacial lakes and streams from multispectral satellite images. To make this assessment, we made coupled field observations of depth and reflectance in coordination with the near-simultaneous acquisition of WV2 images. A spectrally based depth retrieval algorithm developed for terrestrial rivers, called optimal band ratio analysis (OBRA), provided strong relation- ships between radiometric quantities and water depth for (1) essentially continuous spectra measured directly in the field; (2) field spectra convolved to match the response functions of the WV2, Landsat 7, MODIS, and ASTER sensors; and (3) spectra extracted from specific WV2 image pixels. Validation of image-derived depth estimates indicated that remotely sensed data can be used to measure supraglacial bathymetry with a high degree of accuracy (ME $<1 \%$ of mean depth) and precision (RMSE $10-23 \%$ of mean depth, Table 3) across a broad range of depths up to $10.45 \mathrm{~m}$. Similar results were reported by Fitzpatrick et al. (2013), who estimated depths in large lakes from MODIS band 1 reflectance values, but the use of higher resolution satellite images in this study allowed more detailed depth information to be retrieved from smaller water bodies. For example, bathymetric maps of meltwater streams produced from WV2 images were spatially coherent and hydraulically reasonable, revealing subtle features of the channel morphology. In addition to enabling refined estimates of storage volumes in lakes, this approach also opens up new possibilities for characterizing the transient flux of meltwater through stream channels to moulins and hence the interior and/or base of the ice sheet.

Though encouraging, our results also pointed to several key limitations of remote sensing techniques. Ideally, a general, robust relationship between depth and reflectance could 


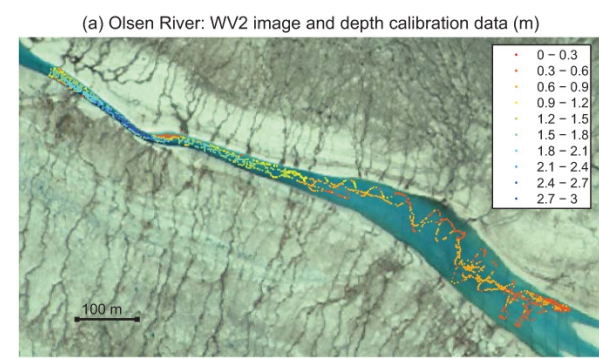

(c) Olsen River: WV2 image and depth calibration data $(\mathrm{m})$

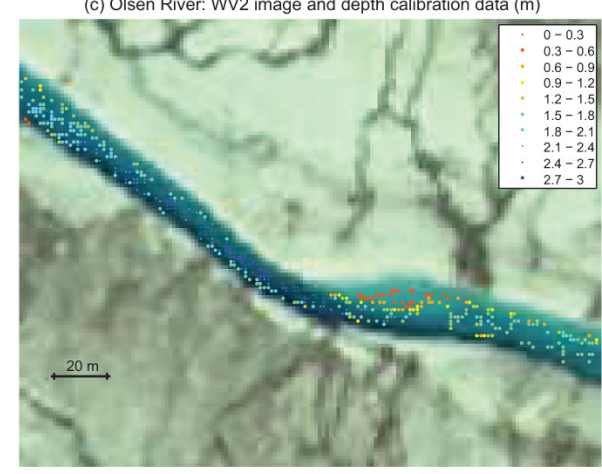

(b) Spectrally-based bathymetry (m)

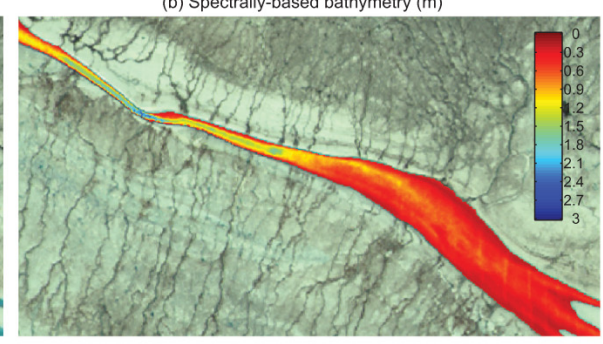

(d) Spectrally-based bathymetry $(\mathrm{m})$

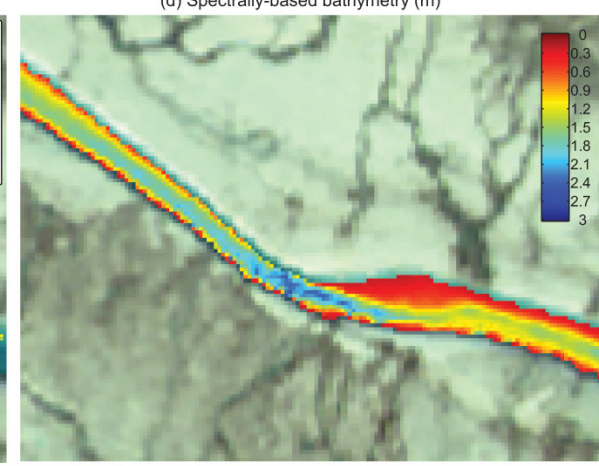

Fig. 7. Field measurements of depth from the Olsen River used for calibration (a, c) and image-derived bathymetry produced by applying the calibration equation from quadratic OBRA to the WV2 image $(\mathbf{b}, \mathbf{d})$. Flow is from right to left.

be identified, calibrated, and applied to the entire ice sheet. This goal remains elusive, however, due to a number of complicating factors. For example, the disparity between OBRA of field spectra and OBRA of image spectra implies that these depth-reflectance relations are scale dependent. Contrary to our expectations, the optimal band ratio was more strongly related to depth for spectra extracted from $2 \mathrm{~m}$ image pixels than for spectra measured directly in the field. This finding suggests that some of the factors considered by Sneed and Hamilton (2011), such as heterogenous substrates, water surface roughness, shadows, and slush, were localized effects that introduced variability to the field spectra but were essentially averaged out over the scale of an image pixel. In general, agreement between field and image spectra was poor, even after atmospheric correction of the image data, with the image spectra tending to have higher reflectance values. In addition, the unexpected selection of NIR bands and negative $X$ vs. $d$ relations resulting from OBRA of image spectra suggest that adjacency effects were salient in the remotely sensed data. These effects can be mitigated by choosing shorter wavelength band combinations in which reflectance from the water is greater, but establishing a calibration relation applicable across images could prove difficult. For example, we found that applying a quadratic OBRA relation based on data drawn from all three of our sites yielded low OP $R^{2}$ values when applied to either of two streams located on separate images. These results imply that a general, image-based depth-reflectance relation might not provide reliable bathymetric information for individual sites, particu- larly shallow streams, and that site-specific calibration would be preferable, if not necessary. In theory, field spectra collected across a range of depths could be used to define a general depth-reflectance relationship in the absence of mixed pixels or atmospheric effects. We were unable to achieve this goal in this initial study, however. Instead, our results point to the need for careful calibration of field measurements and image pixel values to consistent radiometric quantities and for accurate atmospheric correction of remotely sensed data.

If these issues can be resolved, our results indicate that spectrally based remote sensing of supraglacial bathymetry could provide information on meltwater storage and flux with an unprecedented level of detail. This study demonstrated the ability to resolve subtle morphologic features, such as the former shorelines of Lake Napoli evident in the WV2 image shown in Fig. 1c or the ice bar on the Olsen River prominent in Fig. 7d, from high spatial resolution image data. Capturing the associated variations in depth, rather than averaging over coarser pixel sizes, would enable more precise estimates of meltwater storage and flux and thus support focused investigations that emphasize the spatial distribution of lakes, streams, and moulins for a given time period. Similarly, the finding, based on OBRA of convolved field spectra, that Landsat 7, MODIS, and ASTER have sufficient spectral resolution for bathymetric mapping bodes well for larger scale, longer term studies. Although these sensors have coarser spatial resolution that would limit such analyses to larger water bodies, our results indicate that accurate depth retrieval 
(a) Olsen River transect

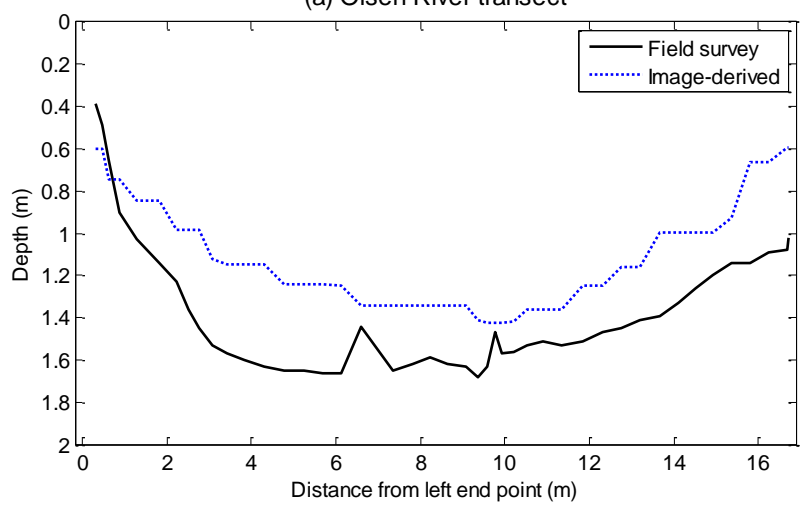

(b) Lake Napoli transect

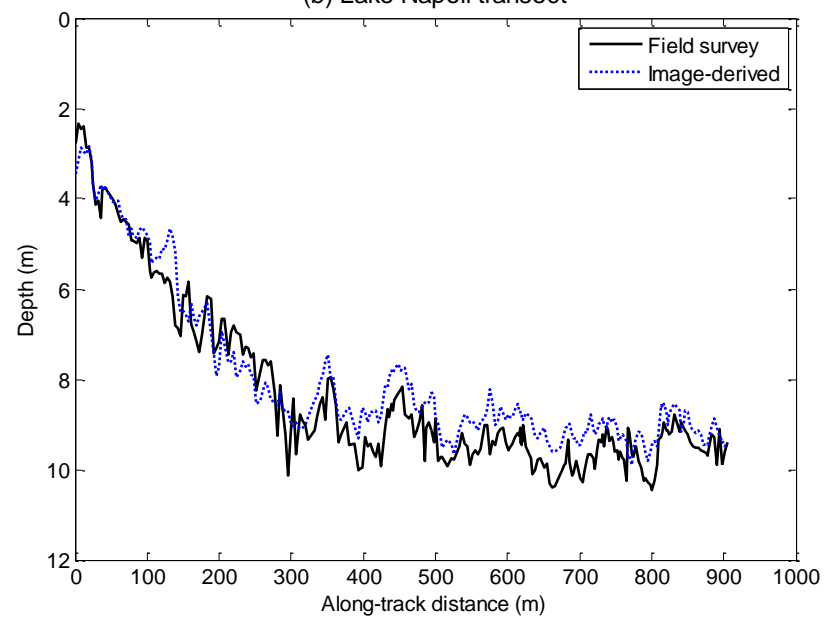

Fig. 8. Transects comparing field surveys and image-derived depth estimates obtained via quadratic OBRA for (a) a cross section of the Olsen River and (b) a boat track from the shore toward the center of Lake Napoli.

should be possible and could facilitate monitoring meltwater on the surface of the GrIS.

\section{Conclusions}

This study demonstrated, for the first time, the feasibility of spectrally based depth retrieval from high spatial resolution commercial satellite images of supraglacial lakes and streams on the GrIS. Given instrumentation with sufficient spatial resolution, optical remote sensing can thus be used to estimate accurately the volume of water stored in not only large lakes but also smaller melt ponds that might go undetected by sensors with coarser pixel sizes. In addition, such data can be used to measure the depth of supraglacial streams and hence characterize the transient flux of meltwater through channels. Future work will focus on addressing the calibration issues identified above, establishing a general relation between depth and reflectance, developing an integrated workflow for scaling up this type of analysis to larger areas of the GrIS, and incorporating the resulting information on meltwater storage and flux into a hydrologic budgeting framework.

Acknowledgements. This investigation was supported by the NASA Cryosphere Program (grant NNX11AQ38G managed by T. Wagner). C. Legleiter and B. Overstreet received additional support through a grant from the Office of Naval Research Littoral Geosciences and Optics Program (N000141010873 managed by T. Drake). M. Tedesco was supported by the NSF grant ARC0909388. Logistical support was provided by CH2M Hill Polar Field Services, the Kangerlussuaq International Science Station, and Air Greenland pilot T. Olsen. Asa Rennermalm loaned the ASD HandHeld 2 spectroradiometer. The Polar Geospatial Center of the University of Minnesota assisted with image acquisition and processing. Field assistance was provided by V. Chu, R. Forster, C. Gleason, S. Moustafa, T. Olsen, L. Pitcher, and A. Rennermalm. A. Pope, G. Hamilton, and an anonymous reviewer provided useful comments that helped to improve our original manuscript.

Edited by: I. M. Howat

\section{References}

Adler-Golden, S. M., Matthew, M. W., Bernstein, L. S., Levine, R. Y., Berk, A., Richtmeier, S. C., Acharya, P. K., Anderson, G. P., Felde, J. W., Gardner, J. A., Hoke, M. L., Jeong, L. S., Pukall, B., Ratkowski, A. J., and Burke, H. K.: Atmospheric correction for short-wave imagery based on MODTRAN 4, SPIE Proc. Ser., 3753, 61-69, 1999.

Bennartz, R., Shupe, M. D., Turner, D. D., Walden, V. P., Steffen, K., Cox, C. J., Kulie, M. S., Miller, N. B., and Pettersen, C.: July 2012 Greenland melt extent enhanced by low-level liquid clouds, Nature, 496, 83-86, 2013.

Box, J. E. and Ski, K.: Remote sounding of Greenland supraglacial melt lakes: implications for subglacial hydraulics, J. Glaciol., 53, 257-265, 2007.

Colgan, W., Steffen, K., McLamb, W. S., Abdalati, W., Rajaram, H., Motyka, R., Phillips, T., and Anderson, R.: An increase in crevasse extent, West Greenland: Hydrologic implications, Geophys. Res. Lett., 38, L18502, doi:10.1029/2011g1048491, 2011.

Dierssen, H. M., Zimmerman, R. C., Leathers, R. A., Downes, T. V., and Davis, C. O.: Ocean color remote sensing of seagrass and bathymetry in the Bahamas Banks by high-resolution airborne imagery, Limnol. Oceanogr., 48, 444-455, 2003.

Fitzpatrick, A. A. W., Hubbard, A. L., Box, J. E., Quincey, D. J., van As, D., Mikkelsen, A. P. B., Doyle, S. H., Dow, C. F., Hasholt, B., and Jones, G. A.: A decade of supraglacial lake volume estimates across a land-terminating margin of the Greenland Ice Sheet, The Cryosphere Discuss., 7, 1383-1414, doi:10.5194/tcd7-1383-2013, 2013.

Leeson, A. A., Shepherd, A., Palmer, S., Sundal, A., and Fettweis, X.: Simulating the growth of supraglacial lakes at the western margin of the Greenland ice sheet, The Cryosphere, 6, 10771086, doi:10.5194/tc-6-1077-2012, 2012.

Legleiter, C. J.: Remote measurement of river morphology via fusion of LiDAR topography and spectrally based bathymetry, Earth Surf. Proc. Land., 37, 499-518, 2012. 
Legleiter, C. J.: Mapping river depth from publicly available aerial images, River Res. Appl., 29, 760-780, 2013.

Legleiter, C. J. and Overstreet, B. T.: Mapping gravel bed river bathymetry from space, J. Geophys. Res.-Earth, 117, doi:10.1029/2012jf002539, 2012.

Legleiter, C. J., Roberts, D. A., Marcus, W. A., and Fonstad, M. A.: Passive optical remote sensing of river channel morphology and in-stream habitat: Physical basis and feasibility, Remote Sens. Environ., 93, 493-510, 2004.

Legleiter, C. J., Roberts, D. A., and Lawrence, R. L.: Spectrally based remote sensing of river bathymetry, Earth Surf. Proc. Land., 34, 1039-1059, 2009.

Legleiter, C. J., Kinzel, P. J., and Overstreet, B. T.: Evaluating the potential for remote bathymetric mapping of a turbid, sand-bed river: 2. Application to hyperspectral image data from the Platte River, Water Resour. Res., 47, W09532, doi:10.1029/2011wr010592, 2011.

Liang, Y.-L., Colgan, W., Lv, Q., Steffen, K., Abdalati, W., Stroeve, J., Gallaher, D., and Bayou, N.: A decadal investigation of supraglacial lakes in West Greenland using a fully automatic detection and tracking algorithm, Remote Sens. Environ., 123, 127-138, 2012.

Luthje, M., Pedersen, L. T., Reeh, N., and Greuell, W.: Modelling the evolution of supraglacial lakes on the West Greenland icesheet margin, J. Glaciol., 52, 608-618, 2006.

Lyzenga, D. R.: Passive Remote-Sensing Techniques for Mapping Water Depth and Bottom Features, Appl. Optics, 17, 379-383, 1978.

Maritorena, S., Morel, A., and Gentili, B.: Diffuse-Reflectance of Oceanic Shallow Waters - Influence of Water Depth and Bottom Albedo, Limnol. Oceanogr., 39, 1689-1703, 1994.

McGrath, D., Colgan, W., Steffen, K., Lauffenburger, P., and Ba$\log$, J.: Assessing the summer water budget of a moulin basin in the Sermeq Avannarleq ablation region, Greenland ice sheet, J. Glaciol., 57, 954-964, 2011.

Nghiem, S. V., Hall, D. K., Mote, T. L., Tedesco, M., Albert, M. R., Keegan, K., Shuman, C. A., DiGirolamo, N. E., and Neumann, G.: The extreme melt across the Greenland ice sheet in 2012, Geophys. Res. Lett., 39, L20502, doi:10.1029/2012g1053611, 2012.
Philpot, W. D.: Bathymetric Mapping with Passive Multispectral Imagery, Appl. Optics, 28, 1569-1578, 1989.

Pineiro, G., Perelman, S., Guerschman, J. P., and Paruelo, J. M.: How to evaluate models: Observed vs. predicted or predicted vs. observed?, Ecol. Model., 216, 316-322, 2008.

Rennermalm, A. K., Moustafa, S. E., Mioduszewski, J., Chu, V. W., Forster, R. R., Hagedorn, B., Harper, J. T., Mote, T. L., Robinson, D. A., Shuman, C. A., Smith, L. C., and Tedesco, M. Understanding Greenland ice sheet hydrology using an integrated multi-scale approach, Environ. Res. Lett., 8, 015017, doi:10.1088/1748-9326/8/1/015017, 2013.

Sneed, W. A. and Hamilton, G. S.: Evolution of melt pond volume on the surface of the Greenland Ice Sheet, Geophys. Res. Lett., 34, L03501, doi:10.1029/2006g1028697, 2007.

Sneed, W. A. and Hamilton, G. S.: Validation of a method for determining the depth of glacial melt ponds using satellite imagery, Ann. Glaciol., 52, 15-22, 2011.

Stumpf, R. P., Holderied, K., and Sinclair, M.: Determination of water depth with high-resolution satellite imagery over variable bottom types, Limnol. Oceanogr., 48, 547-556, 2003.

Tedesco, M. and Steiner, N.: In-situ multispectral and bathymetric measurements over a supraglacial lake in western Greenland using a remotely controlled watercraft, The Cryosphere, 5, 445452, doi:10.5194/tc-5-445-2011, 2011.

Tedesco, M., Luthje, M., Steffen, K., Steiner, N., Fettweis, X., Willis, I., Bayou, N., and Banwell, A.: Measurement and modeling of ablation of the bottom of supraglacial lakes in western Greenland, Geophys. Res. Lett., 39, L02502, doi:10.1029/2011GL049882, 2012.

Tedesco, M., Fettweis, X., Mote, T., Wahr, J., Alexander, P., Box, J. E., and Wouters, B.: Evidence and analysis of 2012 Greenland records from spaceborne observations, a regional climate model and reanalysis data, The Cryosphere, 7, 615-630, doi:10.5194/tc7-615-2013, 2013.

Yang, K. and Smith, L. C.: Supraglacial Streams on the Greenland Ice Sheet Delineated From Combined Spectral-Shape Information in High-Resolution Satellite Imagery, IEEE Geosci. Remote Sens., 10, 801-805, 2013. 